\title{
Variação dos parâmetros físicos, químicos e biológicos da água em um sistema de irrigação localizada
}

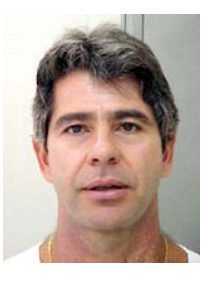

Túlio A. P. Ribeiro'; Rogério P. da S. Airoldi ${ }^{2}$; José E. S. Paterniani ${ }^{3} \&$ Marcelo J. M. da Silva ${ }^{4}$

1 FEAGRI/UNICAMP. CP 6011, Severino vaz, S/N. CEP 13083-970, Campinas, SP. Fone: (19) 3788-1029, Fax (19) 3788-1010. E-mail: tulior@agr.unicamp.br (Foto)

2 FEAGRI/UNICAMP. E-mail: rairoldi@agr.unicamp.br

${ }^{3}$ FEAGRI/UNICAMP. Fone: (19) 3788-1019, Fax (19) 3788-1010. E-mail: pater@agr.unicamp.br

${ }^{4}$ FEAGRI/UNICAMP. Fone: (19) 3788-2371. E-mail: moreiradasilva@engineer.com

Protocolo $134-14 / 8 / 2003$ - Aprovado em 25/2/2005

\begin{abstract}
Resumo: $O$ presente trabalho teve como objetivo pesquisar, uma fonte hídrica superficial utilizada em um sistema de irrigação por gotejamento, com o fim de se analisar a variação temporal, durante um ano, dos principais parâmetros físicos, químicos e biológicos da sua água e que causam problemas de entupimento nos emissores: sólidos suspensos, turbidez, $\mathrm{pH}$, ferro, sulfetos, condutividade elétrica, sólidos dissolvidos, dureza, índice de Langelier, algas e bactérias Os critérios para avaliação das impurezas presentes na água de irrigação se basearam em estudos realizados por Bucks \& Nakayama (1986), no sentido de dar uma orientação de caracter quantitativo que propuseram uma classificação da água, indicando critérios para avaliação do risco de entupimento dos emissores nos sistemas de irrigação localizada. Os resultados mostraram que os parâmetros químicos apresentaram médio risco de obstrução aos emissores, foram $\mathrm{pH}$, ferro e sulfetos, enquanto os parâmetros físicos e biológicos analisados indicaram baixo risco de entupimento dos emissores. Constatou-se correlação dos resultados entre os parâmetros físicos, turbidez e sólidos suspensos totais e o parâmetro biológico algas, com sólidos suspensos totais.
\end{abstract}

Palavras-chave: índice de langelier, qualidade de água, entupimento

\section{Variation of physical, chemical and biological parameters of water in a trickle irrigation system}

\begin{abstract}
This work had the objective to study a superficial water source utilized in a trickle irrigation system. The principal physical, chemical and biological parameters of the irrigation water that caused problems of obstrution in emitters: $\mathrm{pH}$, turbidity, suspensded solids, dissolved solids, EC, hardness, Langelier index, algae and bacterium were analysed during the year. The evaluation criterion of the impurities present in the irrigation water were based on the studies conducted by Bucks \& Nakayama (1986), in order to give quantitative orientation of risk of obstruction of drippers in trickle irrigation systems. The chemical factors which showed moderate clogging risk to the emitters were: $\mathrm{pH}$, total iron and sulphite concentration. All the other analysed parameters resulted in values that did not present obstruction risk to the emitters. A correlation was found between the physical parameters-turbidity and suspended solids and the biological parameters- algae and total suspended solids.
\end{abstract}

Key words: trickle irrigation, water quality, clogging

\section{INTRODUÇÃO}

Por se tratar de um sistema de irrigação tecnicamente eficiente e econômico com relação ao consumo de água e energia, a irrigação localizada tem recebido especial atenção por parte de agricultores irrigantes e pesquisadores e, embora apresente diversas vantagens comparativas em relação a outros, como economia de água, facilidade e eficiência na injeção de fertilizantes, menor exigência de mão-de-obra e redução dos riscos de contaminação de alimentos por organismos patogênicos (Paterniani et al., 1994) os problemas essenciais para sua implantação estão relacionados à qualidade da água a ser utilizada. 
As principais causas de entupimento de emissores foram descridas por Gilbert et al. (1979) em três grupos essenciais: entupimento de origem química, física e biológica. A determinação da causa exata de entupimento de emissores, no entanto, pode ser complexa, uma vez que vários agentes presentes na água podem interagir com outros, agravando o problema de entupimento (Ravina et al., 1992).

Os contaminantes presentes na água de irrigação, como algas, areia e silte, entre outros, devem ser removidos adequadamente, para não ocasionar queda na performance do sistema de irrigação (Pitts et al., 1990).

As impurezas de natureza física, ou seja, partículas inorgânicas em suspensão, como silte, areia, argila e matéria orgânica e fragmento de plantas, resíduos animais etc, podem bloquear ou se acumularem nos emissores, causando entupimento.

As substâncias químicas dissolvidas na água de irrigação, por exemplo, o carbonato de cálcio e o sulfeto de cálcio em altas concentrações, podem precipitar e eventualmente formar incrustações nas paredes das tubulações e emissores, restringindo a passagem da água. Problemas com incrustações e corrosão das tubulações são freqüentes quando se utilizam águas subterrâneas. As incrustações são depósitos de matéria orgânica e inorgânica que se aderem às superfícies dos equipamentos de irrigação localizada e restrigem a passagem de água através das tubulações e saídas de água dos emissores. As suspensões que mais comumente podem produzir essas incrustações são: as areias, silte, os carbonatos, o ferro, e os organismos biológicos.

Segundo Bucks \& Nakayama (1986) é mais provável a ocorrência de obstrução de emissores quando se utiliza água com valores de $\mathrm{pH}$ maiores que 8 , que corresponde ao $\mathrm{pH}$ de uma água em equilíbrio com calcário finamente moído.

Matsura et al. (1989) citam, em seu trabalho que a ferrugem (limo ferroso) pode desenvolver-se pela ação de bactérias ferruginosas que infectam a água, mesmo que o conteúdo de ferro na água seja baixo (menos de $1 \mathrm{ppm}$ ). Sulfeto (lodo de enxofre) pode ocorrer da mesma maneira que a ferrugem, em águas que contenham sulfetos, sobretudo, sulfeto de hidrogênio. Em águas superficiais em geral não é problema, podendo ocorrer com maior freqüência em águas subterrâneas.

Nas condições da região de Campinas, o predomínio do uso de fontes de águas superficiais, aliado à alta freqüência de temperaturas na faixa ótima para o desenvolvimento de microrganismos (predominantemente algas e bactérias) resulta em elevado risco de entupimento de origem biológica para os sistemas de irrigação (Resende et al., 2001).

Este trabalho foi realizado com o objetivo de apresentar e discutir os principais resultados obtidos através de análises de laboratório, efetuadas em amostras de água superficial de um reservatório, durante um ano, utilizada em um sistema de irrigação localizada por gotejamento.

\section{MATERIAL E MÉTODOS}

A investigação experimental foi realizada no município de Campinas, Estado de São Paulo. A região tem altitude média de $640 \mathrm{~m}$, latitude $22^{\circ} 48^{\prime} 57^{\prime \prime} \mathrm{S}$ e longitude de $47^{\circ} 03^{\prime} 33^{\prime \prime} \mathrm{W}$. A água usada no experimento provinha de um reservatório de $2500 \mathrm{~m}^{3}$, constituído de um pequeno açude, que é abastecido pelo bombeamento de água de uma pequena represa, onde ocorre a contribuição hídrica de outras nascentes que a cercam.

$\mathrm{Na}$ área experimental foi montado um sistema de irrigação por gotejamento, composto de uma motobomba centrífuga, um controlador automático de irrigação, duas válvulas elétricas com solenóide, gotejadores, dois reguladores de pressão, sistema de injeção de fertilizantes, constituído de uma bomba dosadora de pistão e um sistema de filtragem composto de um filtro de disco de 130 microns e diâmetro de $25,4 \mathrm{~mm}$ da marca Amiad.

Os ciclos de aplicação de água foram feitos através de um controlador de irrigação programado para acionar o sistema duas vezes ao dia, isto é, pela manhã e no final da tarde, pelo tempo de duas horas; fazia-se a limpeza do filtro sempre que o diferencial de pressão era de $40 \mathrm{kPa}$.

O emissor era o Streamline 80, fabricado com polietileno de baixa densidade e o sistema de emissores tipo labirinto, espaçados $30 \mathrm{~cm}$, espessura da parede de $0,200 \mathrm{~mm}$ e diâmetro interno da tubulação de $16,0 \mathrm{~mm}$.

As amostras de água eram coletadas na linha principal de irrigação, em um ponto localizado antes do sistema injetor de fertilizantes. A qualidade da água foi avaliada nas quatro estações do ano, em quatro etapas, em que a primeira etapa da pesquisa, realizada de 29 de junho a 30 de julho, correspondia a um mês típico de inverno, estação esta caracterizada por baixas precipitações e cuja temperatura da água ficou na média de $22,5^{\circ} \mathrm{C}$, com 10 amostragens realizadas durante o período, enquanto a segunda etapa foi realizada de 5 de novembro a 13 de dezembro, na primavera, estação esta caracterizada por aumento de precipitação, temperatura da água na média de $26,3{ }^{\circ} \mathrm{C}$, quando então se fizeram 12 amostragens; a terceira etapa se estendeu de 28 de fevereiro a 27 de março, com alta precipitações e temperatura da água na média de $28,2{ }^{\circ} \mathrm{C}$; nesta fase foram realizadas 9 amostragens, ao longo de 30 dias; enfim, na quarta e última fase de 9 de maio a 6 de junho, a temperatura da água ficou na média de $21,7^{\circ} \mathrm{C}$; realizaram-se 10 amostragens tirando-se, no total 41 amostrasm, cujo número variou porque os dias de amostragem oscilaram de um período para outro.

Foram avaliados os fatores mais importantes relacionados com a qualidade de água para irrigação localizada e que podem causar obstrução nos gotejadores, como pH, sólidos em suspensão (Ss), turbidez, condutividade elétrica (CE), sólidos dissolvidos, ferro total $(\mathrm{Fe})$, sulfetos de hidrogênio $\left(\mathrm{H}_{2} \mathrm{~S}\right)$, manganês (Mn), dureza, índice de Langelier e concentração de algas e bactérias.

A classificação da água para o sistema de irrigação localizada em relação a problemas de entupimento devido a fatores físicos, químicos e biológicos, seguiu recomendações de Bucks \& Nakayama (1986) conforme Tabela 1.

A determinação dos valores de sólidos dissolvidos na água foi realizada através da razão de proporcionalidade entre os valores de condutividade elétrica medidos e este parâmetro. A relação para determinação dos sólidos dissolvidos é dada pela Eq. 1:

$$
\mathrm{SD}=\mathrm{CE} \times 640
$$


Tabela 1. Classificação da água de irrigação segundo Nakayama \& Bucks (1986)

\begin{tabular}{lccc}
\hline \multirow{2}{*}{ Fatores de Entupimentos } & \multicolumn{3}{c}{ Níveis de Risco } \\
\cline { 2 - 4 } & Baixo & Moderado & Severo \\
\hline \multirow{3}{*}{ Sólidos em suspensão } & $<50$ & $50-100$ & $>100$ \\
\hline \multirow{3}{*}{ pH } & $<7$ & Químico* \\
Sólidos dissolvidos & $<500$ & $7-80-2000$ & $>2000$ \\
Ferro total & $<0,2$ & $0,2-1,5$ & $>1,5$ \\
Manganês & $<0,1$ & $0,1-1,5$ & $>1,5$ \\
Sulfeto de hidrogênio & $<0,2$ & $0,2-2,0$ & $>2,0$ \\
\hline & & Biológico \\
Pop. bact. (NMP $\mathrm{mL}^{-1}$ ) & $<10000$ & $10000-50000$ & $>50000$ \\
\hline
\end{tabular}

* Unidades dos parâmetros físicos e químicos estão em $\mathrm{mg} \mathrm{L}^{-1}$

em que:

$\mathrm{SD}$ - sólidos dissolvidos $\left(\mathrm{mg} \mathrm{L}^{-1}\right)$

$\mathrm{CE}$ - condutividade elétrica $\left(\mathrm{mS} \mathrm{cm}^{-1}\right)$

A avaliação dos sólidos suspensos totais foi utilizada pelo método gravimétrico.Na determinação da turbidez utilizou-se o método de turbidez nefelométrico e, quanto à análise dos problemas de entupimento relacionados dos bicarbonatos $(\mathrm{Bc})$, utilizou-se o índice de saturação de Langelier para avaliar o risco de precipitação de $\mathrm{CaCO}_{3}$, proposto por Bucks \& Nakayama (1986); trata-se da relação do $\mathrm{pH}$ medido na água de irrigação $\left(\mathrm{pH}_{\mathrm{m}}\right)$ e do $\mathrm{pH}$ calculado $\left(\mathrm{pH}_{\mathrm{c}}\right)$. $\mathrm{O}_{\mathrm{cH}}$ é calculado a partir da concentração $\mathrm{HCO}_{3}^{-}, \mathrm{Ca}^{+2}$ e concentração total de sais na água $\mathrm{O} \mathrm{pH}_{\mathrm{c}}$ também está correlacionado com a temperatura da água. $\mathrm{Se} \mathrm{pH}_{\mathrm{m}}>\mathrm{pH}_{\mathrm{c}}, \mathrm{CaCO}_{3}$ poderá ser depositado a partir da solução, o que causará problemas de entupimento; se, no entanto $\mathrm{pH}_{\mathrm{m}}<\mathrm{pH}_{\mathrm{c}}, \mathrm{CaCO}_{3}$ não precipitará. Para Ayers e \& Westcot (1991) o índice de Langelier indica tendência de precipitação do $\mathrm{CaCO}_{3}$ presente na água de irrigação; para valores positivos existe tendência do $\mathrm{CaCO}_{3} \mathrm{se}$ precipitar, enquanto para valores negativos o $\mathrm{CaCO}_{3}$ se mantém em solução.

Para classificação da água do reservatório com relação à dureza, utilizou-se o critério proposto em trabalho realizado por Pitts et al. (1990), no qual eles classificam água com baixo risco de entupimento quando a dureza é menor que $150 \mathrm{mg} \mathrm{L}^{-1} \mathrm{de}$ $\mathrm{CaCO}_{3}$, médio para valores maiores que 150 , menores que $300 \mathrm{e}$ alto para valores acima de $300 \mathrm{ppm}$.

A determinação da população bacteriana foi realizada pelo método de contagem em placa de Petri, utilizando-se ágar (triptona, glucose e extrato de levedura) como meio de cultura e tempo de contagem de $48 \mathrm{~h}$ (APHA, 1992).

Por fim, a contagem de algas se deu pelo método de Sedgwick-Rafter, de acordo com o APHA (1985).

\section{RESULTADOS E DISCUSSÃO}

Os resultados dos parâmetros analisados na água do reservatório durante as 4 estações do ano estão apresentados nas Tabelas 2 e 3. O resultado de cada parâmetro analisado corresponde à amostra coletada na data citada, a partir dos quais é possível qualificar a água utilizada para irrigação no período em questão, quanto ao risco potencial de obstrução dos gotejadores.

De forma geral, diz-se que a água do reservatório apresentou, nesta primeira etapa da pesquisa, boa qualidade para abastecer um sistema de irrigação por gotejamento e os resultados estão apresentados na Tabela 2, exceto por alguns fatores químicos que apresentaram moderado risco de obstrução aos emissores, entre eles o pH, concentração de ferro total e sulfetos, todos os outros parâmetros de qualidade de água analisados resultaram em valores que não apresentam risco de entupimento aos gotejadores, segundo a classificação de Bucks \& Nakayama (1986).

De acordo com trabalho de Pitts et al. (1990), os valores da dureza da água do reservatório são, neste período, considerados de baixo potencial de entupimento com relação à formação de precipitados de $\mathrm{CaCO}_{3}$, o que também pode ser confirmado através dos resultados dos valores do índice de Langelier calculado, que foi negativo, indicando que não há tendência de formação de precipitados, de acordo com Ayers \& Westcot (1991).

Assim como a concentração de sólidos suspensos, os valores obtidos de turbidez também foram baixos, indicando que no período a água apresentou boa qualidade. A variação da turbidez esteve entre 3,88 e 1,82 NTU.

Os valores da condutividade elétrica indicaram que a água utilizada para a irrigação tem salinidade muito baixa e pouco variou ao longo da primeira etapa do projeto, confirma-se quando se observa que os valores de sólidos dissolvidos na água apresentaram baixo risco de entupimento.

As algas foram quantificadas em função de quantidade por volume. Os altos valores do desvio padrão e, principalmente, do coeficiente de variação, indicam grande variação da quantidade de algas presentes na água cujos dados estão apresentados na Tabela 2. De fato, a maior concentração medida foi de 1295 algas $\mathrm{cm}^{-3} \mathrm{e}$ a menor, de 165 algas $\mathrm{cm}^{-3}$.

$\mathrm{Na}$ segunda etapa de estudos a qualidade da água do reservatório apresentou mudanças significativas em diversos parâmetros analisados, as quais promoveram queda na qualidade da água de irrigação, evidenciada principalmente pelo aumento da concentração de sólidos suspensos totais, turbidez, ferro, sulfetos e algas. Referidas mudanças ocorreram porque nesta etapa começou a fase de chuvas na região. Apesar do aumento nos valores médios desses parâmetros, apenas a concentração de sulfetos elevou o risco de entupimento dos emissores, de moderado para alto.

Os parâmetros condutividade elétrica e dureza da água sofreram decréscimo e menor variação dos valores quando comparados aos dados obtidos na primeira etapa (Tabela 2A). Portanto a dureza da água do reservatório na segunda fase continuou apresentando baixo potencial de entupimento com relação à formação de precipitados de $\mathrm{CaCO}_{3}$, segundo classificação de Pitts et al. (1990).

O Índice de Langelier médio obtido na segunda etapa foi idêntico àquele da primeira fase, com valor de -1,95; no entanto, foram obtidos valores superiores tanto de desvio padrão, de 0,42 , quanto do coeficiente de variação, de $21,53 \%$, cujos resultados estão na Tabela 2. 
Tabela 2. Análises da água do reservatório realizadas no período de 29/6/01 a 30/7/01 (A), primeira etapa da pesquisa, e de 5/11/ 2001 a 13/12/2001 (B), segunda etapa da pesquisa

\begin{tabular}{|c|c|c|c|c|c|c|c|c|c|c|c|}
\hline \multirow{3}{*}{ № de Ensaios e Datas } & \multicolumn{11}{|c|}{ Parâmetros da Água de Irrigação* } \\
\hline & \multicolumn{2}{|c|}{ Físicos } & \multicolumn{7}{|c|}{ Químicos } & \multicolumn{2}{|c|}{ Biológicos } \\
\hline & $\begin{array}{c}\mathrm{SS} \\
\left(\mathrm{mg} \mathrm{L}^{-1}\right)\end{array}$ & $\begin{array}{l}\text { Turb. } \\
\text { (NTU) }\end{array}$ & $\mathrm{pH}$ & $\begin{array}{l}\text { Ferro } \\
\left(\mathrm{mg} \mathrm{L}^{-1}\right)\end{array}$ & $\begin{array}{l}\text { Sulfeto } \\
\left(\mathrm{mg} \mathrm{L}^{-1}\right)\end{array}$ & $\begin{array}{c}\mathrm{CE} \\
\left(\mathrm{mS} \mathrm{cm}^{-1}\right)\end{array}$ & $\underset{\left(\mathrm{mg} \mathrm{L}^{-1}\right)}{\mathrm{SD}}$ & $\begin{array}{l}\text { Dureza } \\
\left(\mathrm{mg} \mathrm{L}^{-1}\right)\end{array}$ & $\begin{array}{c}\text { Índice } \\
\text { Langelier }\end{array}$ & $\begin{array}{c}\text { Algas } \\
\left(\mathrm{n}^{0} \mathrm{~cm}^{-3}\right)\end{array}$ & $\begin{array}{l}\text { Bactérias } \\
\left(\mathrm{n}^{\mathrm{o}} \mathrm{cm}^{-3}\right)\end{array}$ \\
\hline
\end{tabular}

A.

\begin{tabular}{|c|c|c|c|c|c|c|c|c|c|c|c|}
\hline 1. $(29 / 6 / 01)$ & 5,0 & 3,88 & 7,1 & 1,0 & 1,0 & 0,056 & 35,84 & 26,63 & $-2,077$ & 165 & 600 \\
\hline 2. $(02 / 7 / 01)$ & & 2,69 & 7,3 & 0,5 & 1,0 & 0,076 & 48,64 & 25,72 & $-1,399$ & 255 & 1000 \\
\hline 3. $(05 / 7 / 01)$ & & 3,51 & 7,7 & 0,5 & 1,0 & 0,056 & 35,84 & 22,96 & $-1,6$ & 1295 & 6500 \\
\hline 4. $(10 / 7 / 01)$ & & 2,2 & 7,2 & 0,5 & 1,0 & 0,067 & 42,88 & 22,04 & $-2,173$ & 480 & 6500 \\
\hline $5 .(12 / 7 / 01)$ & & 3,39 & 7,1 & 0,5 & 1,0 & 0,045 & 28,8 & 22,04 & $-2,34$ & 770 & 6500 \\
\hline 6. $(16 / 7 / 01)$ & 3,0 & 1,82 & 7,2 & 0,4 & 1,0 & 0,05 & 32,0 & 22,68 & $-2,22$ & 705 & 680 \\
\hline 7. $(19 / 7 / 01)$ & 1,0 & 2,31 & 7,7 & 0,5 & 1,0 & 0,067 & 42,88 & 21,12 & $-1,676$ & 315 & 270 \\
\hline 8. $(23 / 7 / 01)$ & 3,0 & 2,29 & 7,2 & 0,4 & 2,0 & 0,062 & 39,68 & 20,22 & $-2,102$ & 460 & 900 \\
\hline 9. $(26 / 7 / 01)$ & 3,0 & 3,41 & 7,3 & 0,4 & 1,0 & 0,047 & 30,08 & 21,0 & $-2,051$ & 310 & 440 \\
\hline 10. $(30 / 7 / 01)$ & 1,0 & 2,8 & 7,5 & 0,5 & 1,0 & 0,063 & 40,32 & 24,84 & $-1,875$ & 215 & 990 \\
\hline Média & 2,67 & 2,83 & 7,33 & 0,52 & 1,10 & 0,06 & 37,70 & 22,93 & $-1,95$ & 497 & 2438 \\
\hline Desvio & 1,51 & 0,68 & 0,23 & 0,18 & 0,32 & 0,01 & 6,33 & 2,14 & 0,30 & 345 & 2812 \\
\hline CV (\%) & 56,46 & 24,18 & 3,09 & 33,68 & 28,75 & 16,80 & 16,79 & 9,32 & 15,57 & 69,46 & 115,36 \\
\hline co de Entupiment & B & $\mathrm{S} / \mathrm{C}$ & $\mathrm{M}$ & M & M & $\mathrm{S} / \mathrm{C}$ & B & $\mathrm{S} / \mathrm{C}$ & $\mathrm{S} / \mathrm{C}$ & $\mathrm{S} / \mathrm{C}$ & B \\
\hline
\end{tabular}

\begin{tabular}{|c|c|c|c|c|c|c|c|c|c|c|c|}
\hline \multicolumn{12}{|l|}{ B. } \\
\hline 1. $5 / 11 / 01)$ & 12,0 & 10,8 & 7,4 & 1,5 & 1,0 & 0,06 & 38,40 & 22,7 & $-2,0373$ & 995 & 1 \\
\hline 2. $(8 / 11 / 01)$ & 8,5 & 8,36 & 7,8 & 1,7 & 2,0 & 0,056 & 35,84 & 21,12 & $-1,587$ & 930 & 1 \\
\hline 3. $(12 / 11 / 01)$ & 13,5 & 9,42 & 7,5 & 1,0 & 2,0 & 0,045 & 28,80 & 18,37 & $-2,133$ & 1340 & 1 \\
\hline 4. $(14 / 11 / 01)$ & 12,5 & 8,9 & 7,0 & 1,0 & 3,0 & 0,057 & 36,48 & 20,2 & $-2,6229$ & 1340 & 1 \\
\hline 5. $(19 / 11 / 01)$ & 10,0 & 7,72 & 7,2 & 1,0 & 2,0 & 0,045 & 28,80 & 20,21 & $-2,0217$ & 1380 & 280 \\
\hline 6. $(22 / 11 / 01)$ & 11,5 & 7,58 & 7,2 & 1,5 & 2,0 & 0,05 & 32,0 & 20,69 & $-2,4125$ & 1015 & 110 \\
\hline 7. $(26 / 11 / 01)$ & 11,0 & 6,19 & 7,4 & 1,0 & 1,0 & 0,051 & 32,64 & 19,75 & $-2,0493$ & 1495 & 1500 \\
\hline 8. $(29 / 11 / 01)$ & 10,0 & 11,9 & 7,7 & 1,5 & 1,0 & 0,049 & 31,64 & 21,12 & $-1,9027$ & 1340 & 32 \\
\hline 9. $(3 / 12 / 01)$ & 11,5 & 6,47 & 7,1 & 0,5 & 1,0 & 0,055 & 35,20 & 21,15 & $-2,4026$ & 1555 & 3200 \\
\hline 10. $(6 / 12 / 01)$ & 11,0 & 9,06 & 8,1 & 1,0 & 4,0 & 0,044 & 28,16 & 21,0 & $-1,4026$ & 1530 & 1300 \\
\hline 11. $(10 / 12 / 01)$ & 9,5 & 7,60 & 7,9 & 0,5 & 1,0 & 0,05 & 32,0 & 21,12 & $-1,5193$ & 1780 & 1000 \\
\hline 12. $(13 / 12 / 01)$ & 10,5 & 5,19 & 6,4 & 1,0 & 9,0 & 0,052 & 26,80 & 21,12 & $-1,3217$ & 1820 & 7000 \\
\hline Média & 10,96 & 8,27 & 7,39 & 1,10 & 2,42 & 0,05 & 32,21 & 20,71 & $-1,95$ & 1377 & 1202 \\
\hline Desvio & 1,37 & 1,91 & 0,46 & 0,38 & 2,27 & 0,01 & 3,68 & 1,04 & 0,42 & 287 & 2065 \\
\hline CV (\%) & 12,53 & 23,13 & 6,23 & 34,89 & 94,13 & 9,96 & 11,42 & 5,00 & 21,53 & 20,88 & 171,81 \\
\hline Risco de Entupimento ${ }^{1}$ & B & $\mathrm{S} / \mathrm{C}$ & $\mathrm{M}$ & M & A & $\mathrm{S} / \mathrm{C}$ & B & $\mathrm{S} / \mathrm{C}$ & $\mathrm{S} / \mathrm{C}$ & $\mathrm{S} / \mathrm{C}$ & B \\
\hline
\end{tabular}

${ }^{1}$ Dos gotejadores, segundo Bucks \& Nakayama (1986), donde: B: baixo risco; M: Médio risco; A: Alto risco e S/C: Sem Classificação
* SS - Sólidos Suspensos; CE - Condutividade Elétrica; SD - Sólidos Dissolvidos

Observou-se acréscimo na quantidade de algas presentes na água e queda substancial da variação das medidas. Provavelmente, a elevação natural das temperaturas e o número de horas diárias de sol possam explicar esta mudança com relação à fase anterior.

Nos resultados apresentados na Tabela 3, referentes a terceira etapa de pesquisa, constata-se elevação dos valores médios dos parâmetros físicos (sólidos suspensos e turbidez), queda dos parâmetros químicos (exceto concentração de sulfetos e índice de Langelier) e também dos parâmetros biológicos, mas as mudanças não foram substanciais, de forma que a classificação do risco de entupimento de cada fator analisado permaneceu inalterada, exceto pelo $\mathrm{pH}$. $\mathrm{O}$ aumento dos parâmetros físicos foi porque nesta etapa ocorreu muitas chuvas e houve uma contribuição da água das enxurradas nas nascentes proveniente das chuvas de verão e, visto que a água do reservatório provinha das nascentes, isto acarretou aumento na concentração de sólidos suspensos na água do reservatório e conseqüentemente um aumento na turbidez.

$\mathrm{Na}$ última etapa a turbidez da água, $\mathrm{pH}$ e concentração de ferro sofreram um decréscimo dos seus valores, enquanto que todos os outros parâmetros analisados aumentaram.

De maneira geral, diz-se que a qualidade da água utilizada para irrigação do sistema de gotejamento variou durante as diferentes épocas do ano, sendo que o risco potencial de entupimento dos gotejadores só foi moderado ou alto com relação aos parâmetros químicos (ferro, sulfetos e $\mathrm{pH}$ ).

Os valores de $\mathrm{pH}$ encontrados no decorrer desta pesquisa são bem parecidos aos estudos já realizados por Testezlaf et al. (1994), que ao verificar a potencialidade do uso de água de reservatórios e rios para uso em sistemas de irrigação por gotejamento em propriedades agrícolas produtoras de hortaliças na região de Campinas, constataram que de 27 fontes hídricas analisadas em $88,9 \%$ delas o $\mathrm{pH}$ era alcalino e 
Tabela 3. Análises da água do reservatório realizadas no período de 28/2/2002 da terceira etapa da pesquisa e de 09/5/2002 a 10/ 06/2002 na quarta etapa da pesquisa

\begin{tabular}{|c|c|c|c|c|c|c|c|c|c|c|c|}
\hline \multirow{3}{*}{ № de Ensaios e Datas } & \multicolumn{11}{|c|}{ Parâmetros da Água de Irrigação* } \\
\hline & \multicolumn{2}{|c|}{ Físicos } & \multicolumn{7}{|c|}{ Químicos } & \multicolumn{2}{|c|}{ Biológicos } \\
\hline & $\begin{array}{c}\mathrm{SS} \\
\left(\mathrm{mg} \mathrm{L}^{-1}\right)\end{array}$ & $\begin{array}{l}\text { Turb. } \\
\text { (NTU) }\end{array}$ & $\mathrm{pH}$ & $\begin{array}{c}\text { Ferro } \\
\left(\mathrm{mg} \mathrm{L}^{-1}\right)\end{array}$ & $\begin{array}{l}\text { Sulfeto } \\
\left(\mathrm{mg} \mathrm{L}^{-1}\right)\end{array}$ & $\begin{array}{c}\mathrm{CE} \\
\left(\mathrm{mS} \mathrm{cm}^{-1}\right)\end{array}$ & $\begin{array}{c}\mathrm{SD} \\
\left(\mathrm{mg} \mathrm{L}^{-1}\right)\end{array}$ & $\begin{array}{l}\text { Dureza } \\
\left(\mathrm{mg} \mathrm{L}^{-1}\right)\end{array}$ & $\begin{array}{c}\text { Índice } \\
\text { Langelier }\end{array}$ & $\begin{array}{c}\text { Algas } \\
\left(\mathrm{n}^{0} \mathrm{~cm}^{-3}\right)\end{array}$ & $\begin{array}{l}\text { Bactérias } \\
\left(\mathrm{n}^{\mathrm{o}} \mathrm{cm}^{-3}\right)\end{array}$ \\
\hline
\end{tabular}

A.

1. $(28 / 2 / 02) \quad 14,0 \quad 7,12 \quad 6,8$

2. $(5 / 3 / 02)-12,5$

$9,13 \quad 6,9$

3. $(7 / 3 / 02) \quad 13,5$

$10,5 \quad 6,6$

4. $(11 / 3 / 02) \quad 15,0$

$9,86 \quad 6,9$

$0,6 \quad 1,0$

$0,047 \quad 30,08$

13,77

$-0,9834$

515

190

5. $(14 / 3 / 02) \quad 19,0$

$11,0 \quad 6,9$

$0,8 \quad 2,5$

$\begin{array}{ll}0,049 & 31,36 \\ 0,05 & 32,0\end{array}$

15,61

$-2,96$

390

$19,29 \quad-2,94 \quad 120$

$0,056 \quad 35,84$

6. $(18 / 3 / 02) \quad 19,0$

$10,0 \quad 7,7$

$0,7-3,0$

$0,042 \quad 26,88$

7. $(21 / 3 / 02) \quad 18,5$

$13,3 \quad 7,8$

0,2

2,0

0,053

33,92

$\begin{array}{llll}1,0 & 3,0 & 0,053 & 33,92\end{array}$

8. $(25 / 3 / 02) \quad 24,5$

$16,9 \quad 7,2$

0,8

5,0

0,047

30,08

9. $(28 / 3 / 02) \quad 22,5$

$13,9 \quad 7,4$

1,0

4,0

0,049

31,36

$11,30 \quad 7,13$

0,74

2,83

0,05

31,72

Desvio $\quad 4,17$

$2,93 \quad 0,42$

0,26

$1,17 \quad 0,01$

2,64

$41,39 \quad 8,33$

8,33

$19,29 \quad-2,64$

655

$\begin{array}{lll}18,37 & -1,81 & 395\end{array}$

$\begin{array}{lll}19,29 & -1,61 & 555\end{array}$

$\begin{array}{lll}19,29 & -2,34 & 315\end{array}$

$\begin{array}{lll}18,37 & -2,11 & 705\end{array}$

$\begin{array}{lll}17,96 & -2,23 & 459\end{array}$

$\begin{array}{lll}1,96 & 0,66 & 179\end{array}$

$10,90 \quad 29,76$

38,97

$\mathrm{S} / \mathrm{C} \quad \mathrm{S} / \mathrm{C} \quad \mathrm{S} / \mathrm{C}$

200

330

10
160

$\begin{array}{lllll}\mathrm{S} / \mathrm{C} & \mathrm{M} & \mathrm{M} & \mathrm{A} & \mathrm{S} / \mathrm{C}\end{array}$

B.

\begin{tabular}{lrrrrrrrrrrr}
$1 .(9 / 5 / 02)$ & 16,0 & 10,0 & 7,3 & 0,5 & 3,0 & 0,051 & 32,64 & 21,12 & $-2,0693$ & 495 & 5400 \\
2. $(13 / 5 / 02)$ & 18,0 & 9,1 & 6,6 & 0,5 & 2,0 & 0,058 & 37,12 & 21,12 & $-2,8193$ & 700 & 3900 \\
3. $(16 / 5 / 02)$ & 22,5 & 8,96 & 6,7 & 1,0 & 2,0 & 0,032 & 20,48 & 22,04 & $-2,5476$ & 205 & 260 \\
4. $(20 / 5 / 02)$ & 19,0 & 8,86 & 7,0 & 1,0 & 2,0 & 0,080 & 51,20 & 21,05 & $-2,2964$ & 695 & 760 \\
5. $(23 / 5 / 02)$ & 21,0 & 10,2 & 6,8 & 0,5 & 16,0 & 0,070 & 44,80 & 21,08 & $-2,6193$ & 410 & 200 \\
6. $(27 / 5 / 02)$ & 22,5 & 8,29 & 6,9 & 0,5 & 2,0 & 0,049 & 31,36 & 21,00 & $-2,4794$ & 950 & 970 \\
7. (29/5/02) & 23,5 & 13,4 & 6,7 & 0,3 & 2,0 & 0,090 & 57,60 & 20,69 & $-3,6354$ & 355 & 3200 \\
8. (4/6/02) & 19,0 & 14,5 & 6,9 & 0,3 & 2,0 & 0,058 & 37,12 & 22,96 & $-2,43$ & 430 & 840 \\
9. (6/6/02) & 18,0 & 7,45 & 6,9 & 0,2 & 2,0 & 0,052 & 33,28 & 20,75 & $-2,43$ & 515 & 780 \\
10. $(10 / 6 / 02)$ & 17,5 & 10,6 & 7,0 & 0,0 & 2,0 & 0,054 & 34,56 & 20,68 & $-2,336$ & 365 & 710 \\
Média & 19,7 & 10,14 & 6,88 & 0,48 & 3,50 & 0,059 & 38,02 & 21,25 & $-2,566$ & 512 & 1702 \\
Desvio & 2,51 & 2,23 & 0,19 & 0,32 & 4,40 & 0,017 & 10,65 & 0,72 & 0,425 & 216 & 1798 \\
CV (\%) & 12,78 & 21,97 & 2,89 & 66,46 & 125,81 & 28,00 & 28,00 & 3,37 & 16,57 & 42,12 & 105,62 \\
co de Entupimento & $\mathrm{B}$ & $\mathrm{S} / \mathrm{C}$ & $\mathrm{B}$ & $\mathrm{M}$ & $\mathrm{A}$ & $\mathrm{S} / \mathrm{C}$ & $\mathrm{B}$ & $\mathrm{S} / \mathrm{C}$ & $\mathrm{S} / \mathrm{C}$ & $\mathrm{S} / \mathrm{C}$ & $\mathrm{B}$ \\
\hline
\end{tabular}

'Dos gotejadores, segundo Bucks \& Nakayama (1986), donde: B: baixo risco; M: Médio risco; A: Alto risco e S/C: Sem Classificação

* SS - Sólidos Suspensos; CE - Condutividade Elétrica; SD - Sólidos Dissolvidos

apresentava risco moderado de entupimento, segundo a mesma classificação adotada nesta pesquisa.

Ayres \& Westcot (1991) citam, que a concentração de Fe total de $0,5 \mathrm{mg} \mathrm{L}^{-1}$, deve ser considerada a máxima permissível, porém quando se incluem os custos e o preço do sistema de filtragem, o valor máximo economicamente viável é de $2 \mathrm{mg} \mathrm{L}^{-1}$. English (1985) relata que problemas com interações bactériaferro têm ocorrido com concentrações de ferro na forma de $\mathrm{Fe}^{+2}$ tão baixa quanto $0,1 \mathrm{mg} \mathrm{L}^{-1}$. Teores deste íon superiores a $0,2 \mathrm{mg} \mathrm{L}^{-1}$, são considerados significativo risco de entupimento. O ferro precipitado forma uma incrustação vermelha, a qual pode aderir ao PVC da tubulação e entupir os emissores. Algumas bactérias filamentosas, como Gallionella e Leptotrhix, oxidam o $\mathrm{Fe}^{+2}$, transformando-o em $\mathrm{Fe}^{+3}$ que pode precipitar-se e provocar entupimento (Pizarro, 1996). Ford \& Tucker (1986) relataram que águas utilizadas em sistemas de irrigação localizada com concentração de ferro maior que 0,4 $\mathrm{mg} \mathrm{L}^{-1}$, contribuem para o crescimento de bactérias férricas filamentosas que causam problemas de obstrução nos emissores; portanto, com tantos valores de referência, com relação à concentração de ferro, o mais indicado, de acordo com esta pesquisa, seria adotar-se o valor adotado por Ayres \& Westcot (1991) e se fazer uma cloração da água para se controlar o desenvolvimento de bactérias férricas no sistema de irrigação, sendo que, para se ter boa eficiência na cloração, o valor do $\mathrm{pH}$ da água terá que ser inferior a 6,5.

Enfatiza-se que a concentração de algas e bactérias apresentou coeficientes de variação elevados durante cada estação do ano, além de variações significativas entre as estações.

A mudança dinâmica da população de algas pode representar um risco ao sistema se não houver um tratamento eficiente da água de irrigação, porque a água que chega aos filtros, freqüentemente possui grande número de algas, as quais serão em grande parte, retidas, porém existem espécies que podem proliferar, dando origem, juntamente com impurezas da própria água, a uma camada biológica nos filtros e gotejadores, o que, com certeza, prejudica o desempenho do equipamento. As espécies mais comuns e que comprometem os sistemas de irrigação localizada são as algas azuis, atualmente designadas 
cianobactérias, as quais tem bom desenvolvimento em temperaturas entre 15 e $30^{\circ} \mathrm{C}$ e pH entre 6 e 9 .

Nas concentrações de bactérias também foram verificadas mudanças rápidas em seus valores, essas mudanças bruscas foram constatadas através das variações das medidas feitas na água do reservatório em laboratório. De acordo com Soares \& Maia (1999) as variações bruscas do crescimento bacteriano se devem às diferentes condições do meio ambiente, como temperatura, $\mathrm{pH}$, necessidade de oxigênio e nutrientes. Esses autores citam, ainda que, para a maioria das bactérias, o $\mathrm{pH}$ ótimo de crescimento se localiza entre 6,5 e 7,5. O pH da água do reservatório variou em média de 7,39 (segunda fase) a 6,88 (terceira fase). Mudanças bruscas de valores com relação a parâmetros biológicos, que geralmente são devidos a fatores relacionados com o meio ambiente, isto pode comprometer a eficiência de filtragem dos sistemas de irrigação localizada e, conseqüentemente, ocorrer problemas de obstrução dos emissores (Nakayama \& Bucks, 1991).

Capra \& Scicolone (1998), avaliando o entupimento em 21 sistemas instalados com microaspersão e gotejamento na região meridional da Itália, observaram redução no entupimento de emissores, quando o valor do índice de Langelier aumentava, ou seja, quando aumentava o risco de precipitação de carbonato de cálcio. Embora apresentando limitações, o índice de Langelier é o mais comumente usado (APHA, 1992).

Para Ayers \& Westcot (1991), o método mais eficaz para se impedir as obstruções provocadas pela precipitação de $\mathrm{CaCO}_{3}$, é controlar o pH da água e limpar periodicamente o sistema, com ácido clorídrico ou ácido sulfúrico.

\section{Correlação entre os parâmetros físicos e biológicos}

Fez-se uma análise de correlação entre os parâmetros físicos e biológicos. As equações apresentadas na Tabela 4, mostram os valores dos coeficientes de correlação (r) para todos os parâmetros analisados. As equações mostraram que o grau de significância entre os parâmetros turbidez em relação a sólidos suspensos (Figura 1) e sólidos suspensos em relação à turbidez (Figura 2) foram com um nível de confiança de 99\% para ambas as equações, já a equação entre os parâmetros algas em relação a sólidos suspensos (Figura 3) o nível de confiança foi de $95 \%$ de acordo com os resultados da analise de variância.

A correlação entre a turbidez e sólidos suspensos e viceversa, pode ser explicado através de estudos feitos por Pitts et al. (1990) cujos pesquisadores citam que; a turbidez é um indicador de sólidos suspensos, mas somente ela não é parâmetro preciso para se determinar o grau de risco de entupimento de emissores para fontes de água superficial. Para Gilbert \& Ford (1986) este parâmetro físico deveria ser analisado conjuntamente em teste de filtragem em laboratório, para poder mensurar o potencial de risco de entupimento de emissores.

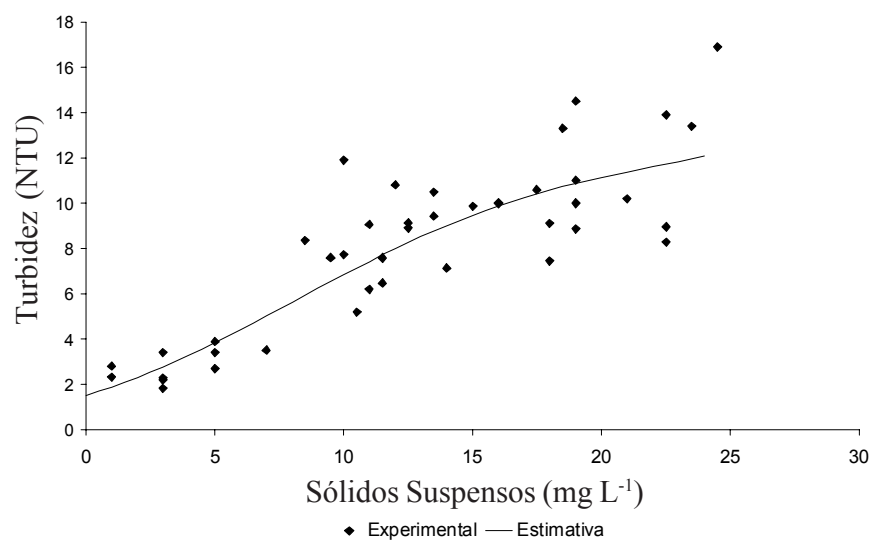

Figura 1. Turbidez versus sólidos suspensos

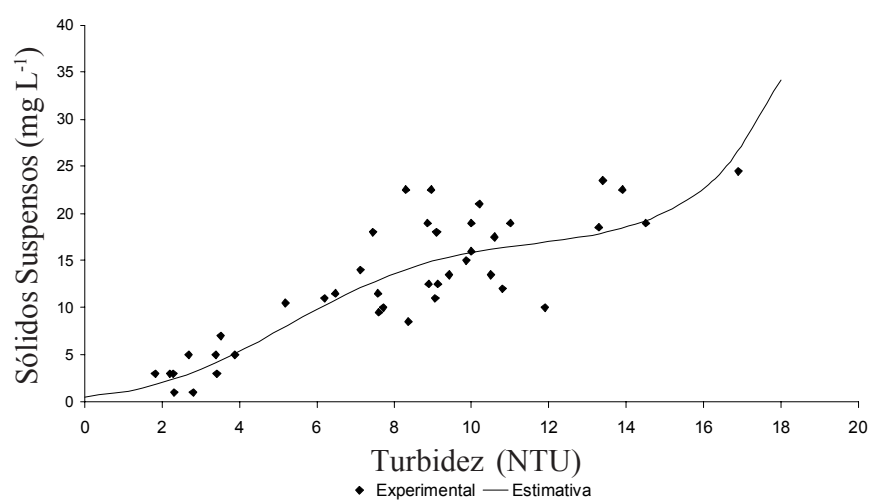

Figura 2. Sólidos suspensos versus turbidez

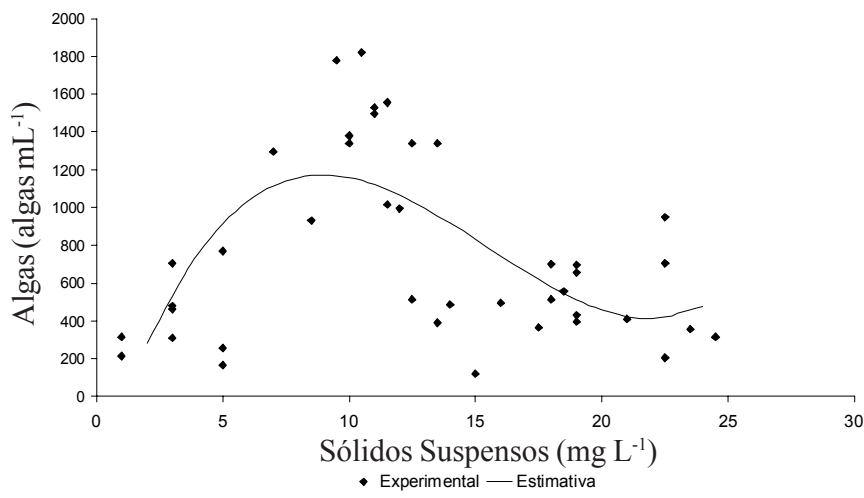

Figura 3. Algas versus sólidos suspensos

A correlação entre algas e sólidos suspensos, observada neste estudo, já foi constatada em trabalhos de Silverman et al. (1983); no presente estudo, os pesquisadores constataram haver correlação com coeficiente elevado entre alguns parâmetros, tais como: de 0,93 entre o número total de partículas e a concentração de algas; de 0,90 entre o número de partículas na faixa de tamanho de 2 a $4 \mu \mathrm{m}$ e a concentração total de algas;

Tabela 4. Equações de correlação entre turbidez, sólidos suspensos e algas obtidas por regressão linear com seus respectivos coeficientes de correlação (r).

\begin{tabular}{|c|c|c|c|}
\hline & Equação & $\mathrm{r}$ & Tipo de Regressão \\
\hline Turb & $=1,5029448 * \operatorname{EXP}\left(0,2287658 * \mathrm{SS}-8.98918 \mathrm{E}-03 * \mathrm{SS}^{2}+1279773 \mathrm{E}-04 * \mathrm{SS}^{3}\right)$ & $0,9136^{*}$ & Exponencial Cúbica \\
\hline & $=0,48075628 * \operatorname{EXP}\left(0,8527342 *\right.$ Turb $-7,044862 \mathrm{E}-02 * \operatorname{Turb}^{2}+2,013 \mathrm{E}-03 *$ Turb $\left.^{3}\right)$ & $0,8961^{*}$ & Exponencial Cúbica \\
\hline Algas & $=-416,6158+410,1762 * \mathrm{SS}-32,21755 *(\mathrm{SS})^{2}+0,6948543 *(\mathrm{SS})^{3}$ & $0,6783^{* *}$ & Cúbica \\
\hline
\end{tabular}

* Existe uma relação entre os parâmetros com um nível de confiança de 99\%; SS - Sólidos Suspensos; **Existe uma relação entre os parâmetros com um nível de confiança de $95 \%$ 
de 0,93 e 0,96 entre o número de partículas nas faixas de tamanho de 10 a $15 \mu \mathrm{m}$ e de 15 a $20 \mu \mathrm{m}$, respectivamente, com a concentração de algas verdes. Os mesmos autores citam também que as algas são responsáveis diretas pelo aumento da turbidez.

\section{CONCLUSÕES}

1. Dos três parâmetros analisados na água de irrigação, o biológico foi o que apresentou maior coeficiente de variação. Este parâmetro analisou os itens concentrações de algas e bactérias, sendo que o segundo apresentou a maior variação.

2. Ocorreu correlação entre os parâmetros físicos turbidez e sólidos suspensos e entre o parâmetro biológico, algas e sólidos suspensos.

\section{AGRADECIMENTOS}

Os autores agradecem, à FAPESP, o auxílio financeiro para a realização deste projeto (Processo: 00/01292-5) e bolsas de estudo concedidas (Processos: 01/02058-9 e 01/01719-1).

\section{LITERATURA CITADA}

APHA, AWWA, WPCF. Standard methods for the examination of water and wastewater. 16 ed. Washington: D.C. 1985 , $1268 \mathrm{p}$.

APHA. Standard methods for examination of water and wastewater. Washington, D.C. 1992

Ayers, R.S.; Westcot, D.W. A qualidade da água na agricultura. Campina Grande: UFPB, 1991.218p.

Bucks, D.A.; Nakayama, F.S. Trickle irrigation for crop Production: design, operation and management. Amsterdam: Elsevier, 1986, 163p.

Capra, A.; Scicolone, B. Water quality and distribution uniformity in drip/trickle irrigation systems, Journal of Agriculturas Engeneering Research, Catania, v.70 p.355-365, 1998.

English, S.D. Filtration and water treatment for micro-irrigation. In. Internacional Drip/Trickle Irrigation Congress, 3, Fresno, Proceedings. St Joseph: ASAE, 1985, p.50-57.

Ford, H.A.; Tucker, D.P.H. Clogging of drip systems from metabolic products of iron and sulfur bacteria. International. Drip Irrigation. 2 Congress Proceedings, San Diego, 1986, p 212-214
Gilbert, R.G.; Nakayama, F.S.; Bucks, D. A. Trickle irrigation: Prevention of clogging. Transactions of the ASAE, v.22, p.514-519, 1979.

Gilbert, R.G.; Ford, H.W. Operational principles/emiter clogging. In: Nakayama, F.S.; Bulks, D.A. Trickle irrigation for crop production. Amsterdam: Elsevier, 1986 cap. 3. p.142-163.

Matsura, E.E.; Testezlaf, R.; Almeida Neto, J.A. Perda de carga nos filtros de areia e tela do sistema de irrigação por gotejamento. In: Congresso Brasileiro de Engenharia Agrícola, 18, 1989, Recife. Anais... Recife: SBEA, 1989, p.584-607.

Nakayama, F.S.; Bucks, D.A. Emitter clogging effects on trickle irrigation uniformity. Transaction of the ASAE, St Joseph, v. 24, p.77-80, 1991.

Paterniani, J.E.S.; Matsura, E.E.; Roston, D.M.; Paula Jr., D.R.; Testezlaf, R.; Ribeiro, T.A.P. Diagnóstico da qualidade da água de irrigação em propriedades produtoras de hortaliças da região de Campinas. In: Congresso Brasileiro de Engenharia Agrícola, 23, 1994, Anais... Campinas: SBEA, 1994.20p.

Pitts, D.J.; Haman, D.Z.; Smajstla, A.G.. Causes and prevention of emitter plugging in microirrigation systems. Gainsville, University of Florifa, Florida Cooperative Extension Service, University of Florida, 1990, 258, p.12 Bulletin

Pizarro, F. Riegos localizados de alta frequencia. 3 ed. Madrid: Ed. Mundi Prensa, 1996. 471p.

Ravina, E.P.; Sofer, Z.; Marcu, A.; Shisha, A.; Sagi, G.. Control of emitter clogging in drip irrigation with wastewater. Irrigation Science, Heidelberg, v.13,129-139, 1992.

Resende, R.S.; Casarini, E.; Folegatti, M.V.; Coelho, R.D. Ocorrência de entupimento de origem biológica em sistema de irrigação por gotejamento. Revista Brasileira de Engenharia Agrícola e Ambiental, Campina Grande, v.5, p.156-160, 2001.

Silverman, G.S.; Nagy, L.A.; Olson, B.H. Variations in particulate matter, algae and bacteria in an Uncovered, finisheddrinking-water reservoir Journal American Water and Wastewater Association, USA v.75, n.4, p.191-195, 1983.

Soares, J.B.; Maia, A.C.F. Água: microbiologia e tratamento. Fortaleza: UFC, 1999. 206p.

Testezlaf, R.; Matsura, E.E.; Roston, D.M.; Paula Jr., D.R.; Paterniani, J.E.; Ribeiro, T. A.P. Potencialidade do uso de irrigação por gotejamento em propriedades agrícolas produtoras de hortaliças da região de Campinas, SP. In: Congresso Brasileiro de Irrigação e Drenagem,10, 1994, Anais... Salvador: SBEA, 1995, p.184-192 